\title{
Submitting and tracking SADJ manuscripts to be facilitated by manuscript management systems - A professional development bulletin
}

SADJ October 2020, Vol. 75 No. 9 p475 - p477

N Metsing

SADA - Head: Professional Development

The South African Dental Journal (SADJ) keeps you abreast of the latest developments in dentistry, and is the only Department of Higher Education and Training accredited scientific dental journal in South Africa for publication of scientific papers, clinical articles, current dento-political information and opinion, and trade information. Members are also able to attain their CDP points by completing the online questionnaires.

All SADJ online CPD Questionnaires are valid for a twoyear period from the date of online publication. If you are not able to load the questionnaire to your courses it may be as a result of expiry.

The SADJ is published 10 times per annum between the months of February and December, that are available electronically. Hard copies are available at a single copy purchase price of R100.00 and postage included is R100 (both VAT inclusive). We would like to emphasize that the sale for SADJ is not limited to SADA members, it is for everyone.

The editorial and professional development team was hard at work to improve manuscript submission, review and general management processes all the way to publication. The whole process is now digitized from beginning to end!

We have gone into a partnership with The Academy of Science of South Africa (ASSAf) to ensure that we make the processes and access much easier for the authors, reviewers and readers.

What are the benefits for users of the journal?

While we used manual processes for only a few months prior to publishing the inaugural issue, and thus quantification of before-and-after improvements is not feasible or practical, the benefits of using an online system to manage manuscripts and peer reviews were immediately apparent to us, as the journal moved to more automated processes. In particular, eight features of such a system have been key to helping us manage the journal's processes, particularly with respect to peer review:

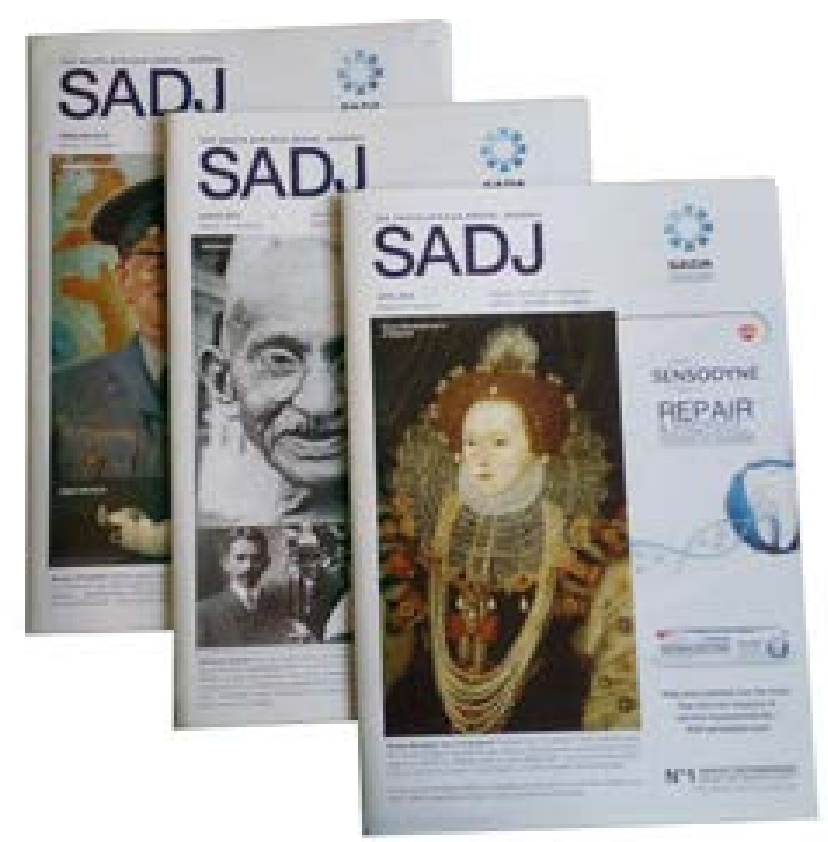

- Authors are now able to load their manuscripts online 24/7 at their own convenience.

- Automated tracking of manuscripts through the peer review workflow.

- Selecting and allocating appropriate peer reviewers.

- Assigning alternative reviewers.

- Sending letters and reminder notifications.

- Facilitating the blinded review process.

- Monitoring and evaluating journal processes.

- Ability to analyse the vital statistics of out process.

\section{THE ACADEMY OF SCIENCE OF SOUTH AFRICA} (ASSAf)

The Academy of Science of South Africa (ASSAf) was inaugurated in May 1996 by the former President of South Africa and patron of the Academy, Nelson Mandela. It was formed in response to the need for an academy of science congruent with the dawn of democracy in South Africa - activist in its mission of using science for the benefit of society. 
The mandate of the Academy encompasses all fields of scientific enquiry and it includes the full diversity of South Africa's distinguished scientists. The Parliament of South Africa passed the Academy of Science of South Africa Act (Act 67 of 2001), as amended, which came into operation in May 2002.

ASSAF is the official national Academy of Science of South Africa and represents the country in the international community of science academies. Since its inception, ASSAf has grown from a small, emergent organisation to a well-established academy.

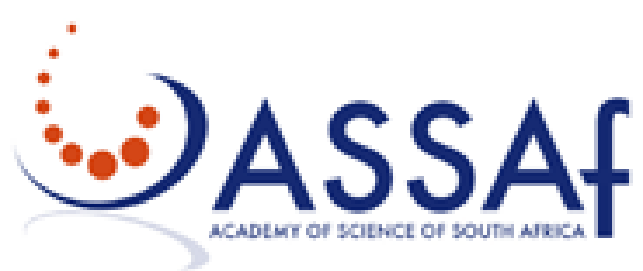

Vision

The Academy of Science of South Africa (ASSAf) aspires to be the apex organisation for science and scholarship in South Africa, recognised and connected both nationally and internationally. Through its Membership which represents the collective voice of the most active scholars in all fields of scholarly enquiry, ASSAf aims to generate evidence-based solutions to national problems.

\section{Mission}

The benefits that the Academy aspires to bring to South Africa (and the wider world) are the sustainable provision of a professionally managed organisation that can mobilise the best intellect, expertise and experience.

These are used to investigate and provide evidencebased solutions to national problems; inspiration and example in science and technology, applied for the benefit of society; international connectedness at the highest level of knowledge and insight; and facilitation of public understanding of the nature, scope and value of the scientific and technological enterprise.

\section{Relevance}

The strategic priorities of the Academy are closely matched to those of the nation. The priorities focus particularly on the need for the greatly enhanced availability of high-level human capital and an increased use of the country's best intellectual expertise in generating evidence-based science advice in support of policy development.

The Academy is aligned to national policy as dictated in the White Paper on Science and Technology and the National Research and Development Strategy. It also seeks, through its studies and convening activities, to address the triple challenges of the reduction of poverty, unemployment and inequality, as enunciated in the National Development Plan (NDP).

\section{Selected benefits}

SADJ has been accepted along with eminent DHET accredited journals on the Khulisa Journals platform, hosted by the Academic of Science Africa (ASSAf).

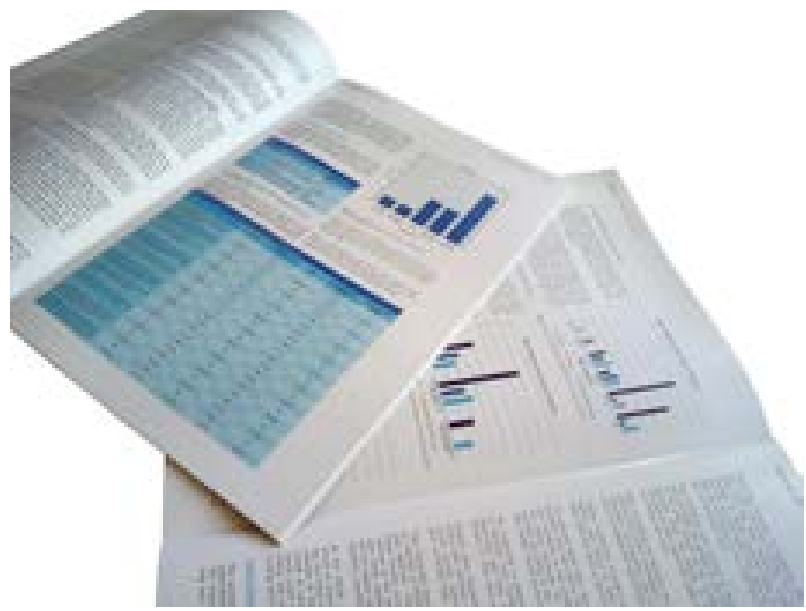

The Public Knowledge Project (PKP) Open Journal Systems (OJS) open source software is used to host the journal. It is the preferred platform for South African academic journals and used by more than 10,000 scholarly journals worldwide. OJS is a comprehensive tool for managing the entire submission and editorial workflow up to the publishing of articles and issues. The automated workflow streamlines the process, and Authors can at any stage check the status of their submitted articles.

All content submitted are managed online, and all email and other communication are captured and stored within the system, for convenient referencing should there be a need in future. Should there be a change in Editor or members of the Editorial Board, the transition will be seamless since all activities and communication are captured by the system.

OJS is integrated with best practice scholarly publishing services such as Crossref, ORCiD, DOAJ, Portico, and more. Registration of DOl's with Crossref, metadata with DOAJ, acknowledgment of authors through ORCiD

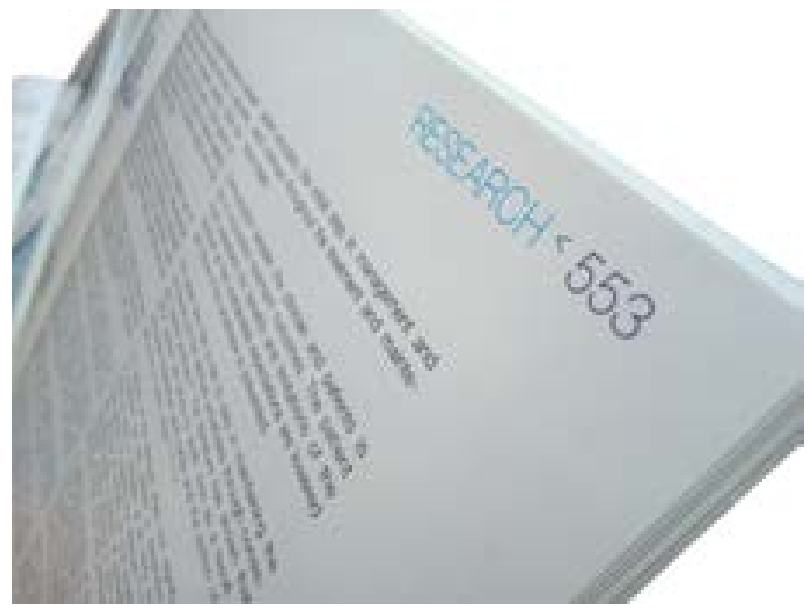


profiles, and digital preservation through Portico, are all automated.

OJS is recommended by Google Scholar for ease of indexing and discoverability. The full text pdfs are indexed, and therefore increases the visibility and impact of the journal. Individual articles can be shared on social media with the click of a button, and the social media mentions and interactions are monitored through the statistics provided The impact of individual articles through the number of downloads and citations and demonstrate the value of SADJ are also monitored.

\section{To submit a new paper to SADJ, do as follows:}

1. If this is your first time using this platform, please Register by completing the online form (once off): https://journals.assaf.org.za/index.php/sadj/user/ register

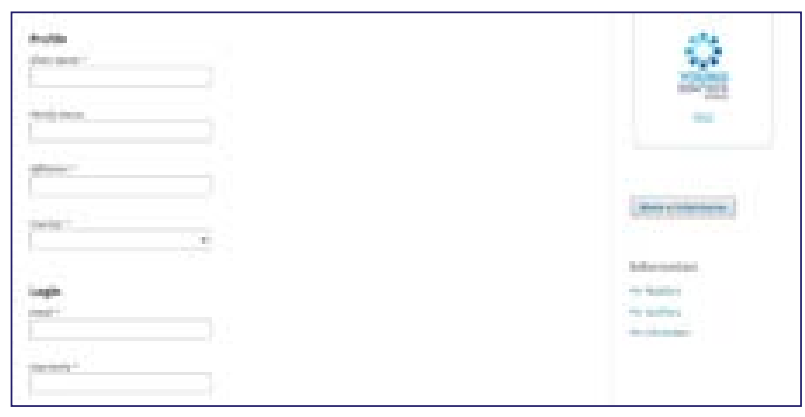

2. Once registered, make sure you are still logged in (Login every time you want to submit a new paper): https://journals.assaf.org.za/index.php/sadj/login

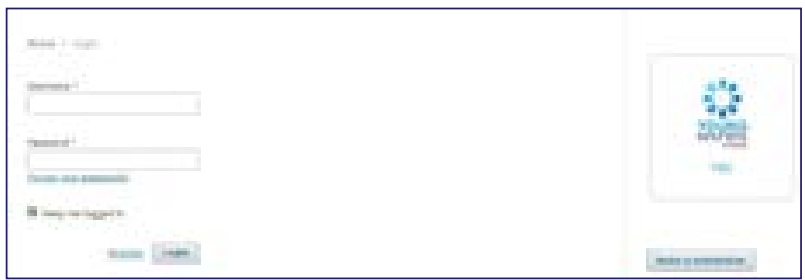

3. Click on Make a Submission on the righthand side of the page.

$$
\text { Make a Submission }
$$

4. Familiarize yourself with the Author Guidelines. Then click on Make a new submission.

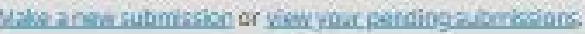

5. Follow the 5 steps as part of the wizard, until the last screen. You will receive a confirmation email once successfully submitted, and the Journal Manager/ Editor will be notified.

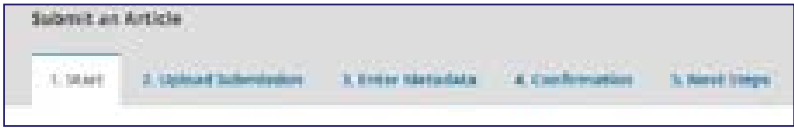

If you are struggling to load/submit kindly email Dumi Ngoepe at SADA on sadj@sada.co.za for assistance.

\section{If you have been selected a reviewer - Follow these steps:}

1. If this is your first time using this platform, please Register by completing the online form (once off): https://journals.assaf.org.za/index.php/sadj/user/ register

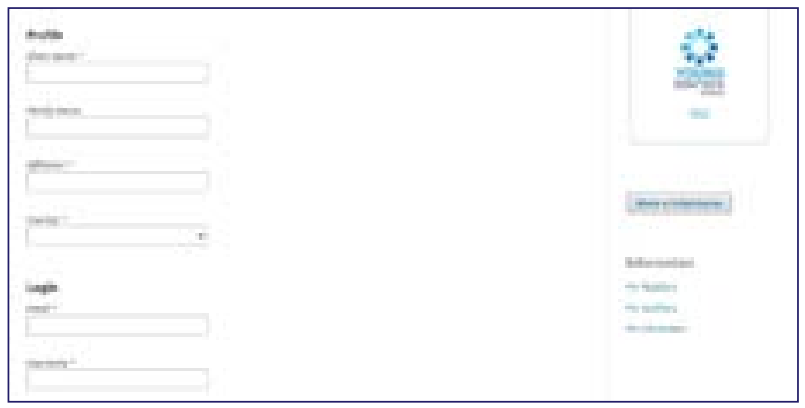

*Kindly tick the last box and insert your reviewing interests as below.

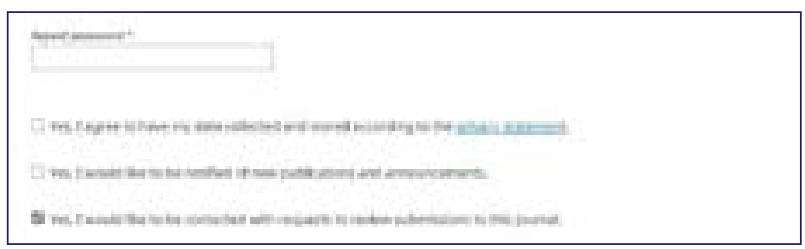

2. After registering you will receive notifications via email for papers sent to you for Review.

3. Once registered, make sure you are still logged in (Login every time you want to access a Review request): https://journals.assaf.org.za/index.php/sadj/login

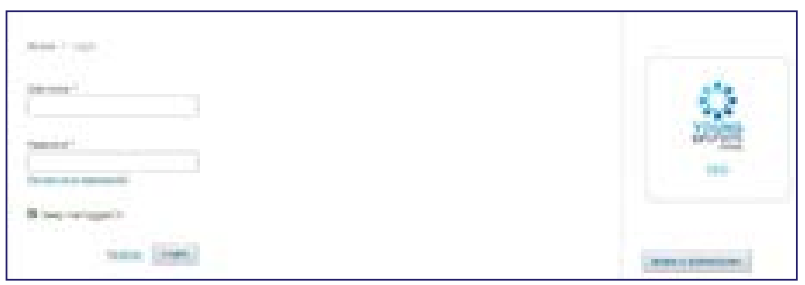

* Regular reminders will be sent to reviewers.

For further information or queries, kindly email Mr Dumi Ngoepe at SADA on sadj@sada.co.za for assistance. 